\title{
Implementing Hospital-Based Baby Boomer Hepatitis C Virus Screening and Linkage to Care: Strategies, Results, and Costs
}

\author{
Barbara J. Turner, MD, MSEd ${ }^{1,2 *}$, Barbara S. Taylor, MD, MSc ${ }^{1,2}$, Joshua T. Hanson, MD, MPH ${ }^{1,2}$, Mary Elizabeth Perez, RMA², \\ Ludivina Hernandez, $\mathrm{CHW}^{2}$, Roberto Villarreal, $\mathrm{MD}^{3}$, Poornachand Veerapaneni, $\mathrm{MD}^{2}$, Kristin Fiebelkorn, MD ${ }^{4}$
}

${ }^{1}$ Department of Medicine, University of Texas Health Science Center at San Antonio, San Antonio, Texas; ' $C e n t e r$ for Research to Advance Community Health, University of Texas Health Science Center at San Antonio, San Antonio, Texas; ${ }^{3}$ University Health System, San Antonio, Texas, ${ }^{4}$ Department of Pathology, University of Texas Health Science Center at San Antonio, San Antonio, Texas.

BACKGROUND/OBJECTIVE: The US Preventive Services Task Force recommends 1-time hepatitis C virus $(\mathrm{HCV})$ screening of all baby boomers (born 1945-1965). However, little is known about optimal ways to implement HCV screening, counseling, and linkage to care. We developed strategies following approaches used for HIV to implement baby boomer HCV screening in a hospital setting and report results as well as costs.

DESIGN/PATIENTS: Prospective cohort of 6140 baby boomers admitted to a safety-net hospital in South Texas from December 1, 2012 to January 31, 2014 and followed to December 10, 2014

PROCEDURES/MEASUREMENTS: The HCV screening program included clinician/staff education, electronic medical record algorithm for eligibility and order entry, opt-out consent, anti-HCV antibody test with reflex HCV RNA, personalized inpatient counseling, and outpatient case man- agement. Outcomes were anti-HCV antibody-positive and HCV RNA-positive results.

RESULTS: Of 3168 eligible patients, 240 (7.6\%) were antiHCV positive, which was more likely $(P<0.05)$ for younger age, men, and uninsured. Of 214 (89.2\%) patients tested for HCV RNA, 134 (4.2\% of all screened) were positive (chronic HCV). Among patients with chronic HCV, 129 (96.3\%) were counseled, $108(80.6 \%)$ received follow-up primary care, and $52(38.8 \%)$ received hepatology care. Five patients initiated anti-HCV therapy. Total costs for start-up and implementation for 14 months were $\$ 286,482$.

CONCLUSIONS: This inpatient HCV screening program diagnosed chronic HCV infection in $4.2 \%$ of tested patients and linked $>80 \%$ to follow-up care. Yet access to therapy is challenging for largely uninsured populations, and most programmatic costs of the program are not currently covered. Journal of Hospital Medicine 2015;10:510-516. (C) 2015 Society of Hospital Medicine

\section{INTRODUCTION}

The baby boomer generation, born from 1945 to 1965 , accounts for $75 \%$ of the estimated 2.7 to 3.9 million persons with chronic hepatitis $\mathrm{C}$ virus (HCV) infection in the US. ${ }^{1-3}$ Most HCV-infected baby boomers do not know that they are infected. ${ }^{4}$ With the advent of bettertolerated, more-effective therapies to treat chronic $\mathrm{HCV}$ infection, ${ }^{5}$ and to reduce rates of complications such as cirrhosis, liver failure, and hepatocellular carcinoma, ${ }^{6}$ universal 1-time screening of baby boomers has been endorsed by the Centers for Disease Control and Prevention (CDC) and the United States Preventive Services Task Force. ${ }^{1,7}$ Hospitalized baby boomers may offer an important target for HCV screening. Our group conducted an anonymous HCV seroprevalence study of nearly 800 patients on general medicine and

*Address for correspondence and reprint requests: Barbara J. Turner, MD, Center for Research to Advance Community Health, University of Texas Health Science Center San Antonio, 7411 John Smith Dr., Suite 1050, San Antonio, TX 78229; Telephone: 210-562-5551; Fax: 210-5625560; E-mail: turner@uthscsa.edu

Additional Supporting Information may be found in the online version of this article.

Received: February 17, 2015; Revised: April 10, 2015; Accepted: April 19, 2015

2015 Society of Hospital Medicine DOI 10.1002/jhm.2376

Published online in Wiley Online Library (Wileyonlinelibrary.com). trauma services of 2 Philadelphia hospitals, and found that $8 \%$ had undiagnosed HCV infection, and $8 \%$ had diagnosed HCV. ${ }^{8}$

Little is known about barriers and facilitators to implementation of universal HCV screening of baby boomers. Lessons from implementing HIV screening offer a useful guide. ${ }^{9}$ First, limited clinician knowledge and confusion about screening guidelines necessitated convenient, well-designed educational programs. ${ }^{10}$ Second, burdensome consent procedures were reduced by opt-out consent for screening supplemented by patient education. 9 Third, electronic medical record (EMR) algorithms minimized burdens on staff by efficiently identifying and flagging eligible persons for screening. ${ }^{11}$ Fourth, ancillary staff support for patient education and linkage to follow-up care increased screening rates compared with usual care by physicians/staff. ${ }^{11}$ Finally, routine human immunodeficiency virus (HIV) testing of inpatients increased rates of diagnosis, especially compared with physician referral systems. ${ }^{12}$

This article describes how HIV screening strategies informed the development in a baby boomer HCV screening and linkage to a care program in a safetynet hospital serving a majority Hispanic population. We report results of the first 14 months of the screening program and linkage to care for chronically HCVinfected persons after a minimum 10 months follow- 
up. We also estimate costs for program implementation and maintenance to inform hospital administrators, healthcare policymakers, and clinicians about resources that may be required to effectively screen hospitalized baby boomers for HCV.

\section{METHODS}

\section{Study Setting}

The HCV baby boomer screening program was pilot tested in November 2012 and launched December 1, 2012 in a 498-bed academic-affiliated hospital of a healthcare system serving the indigent population of South Texas.

\section{Project Development Phase}

From October 1, 2012 to November 30, 2012, project infrastructure development and provider/staff education were conducted. A half-hour PowerPoint lecture (in person or online) was developed about HCV epidemiology, birth-cohort HCV screening guidelines, newer treatment modalities, and screening program components. Lectures were delivered to departmental chairs at the affiliated medical school, departmental grand rounds, and the hospital's nursing supervisors. One-on-one informational meetings were also held with hospital administrators and staff.

With the hospital's information technology team, screens were developed to identify eligible baby boomers from up to 7 years of previous inpatient and outpatient encounters in the EMR from: birth year (19451965) and no prior diagnosis of HCV infection (070.41, 070.44, 070.51, 070.54, 070.7x, V02.62) or any type of completed test for HCV. The algorithm also excluded patients admitted to psychiatry due to lack of decision-making capacity or patients with a poor prognosis such as metastatic cancer. An audit of 100 consecutive excluded patients identified all as legitimate.

A new laboratory order for HCV screening was developed by laboratory administrators and pathology faculty for an anti-HCV antibody test followed by reflex HCV RNA testing for positive results per CDC recommendations. ${ }^{13}$ The anti-HCV test was performed on serum or ethylenediaminetetraacetic acid plasma using the Advia Centaur HCV Assay (Bayer HealthCare LLC, Tarrytown, NY). This assay has excellent sensitivity $(99.9 \%)$ and specificity $(97.5 \%) .{ }^{14,15}$ The HCV RNA assay was performed using quantitative real-time polymerase chain reaction (PCR) using the COBAS AmpliPrep/COBAS TaqMan HCV test (Roche Molecular Systems, Pleasanton, CA). Use of plasma preparation tubes (PPTs) (BD Vacutainer PPT tubes; Becton, Dickinson and Co., Franklin Lakes, NJ) permitted both anti-HCV antibody and HCV PCR testing to be performed on the same specimen when anti-HCV antibody was detected, eliminating a second blood draw for the PCR test. For patients eligible for screening, an EMR algorithm was created to add an HCV screening order to over 50 different admission order sets.
To educate patients newly diagnosed with HCV infection, we developed an interactive, low-literacy, educational program in Spanish and English for an electronic tablet device that addressed: HCV epidemiology, transmission prevention, factors that can accelerate chronic HCV infection, and management/ treatment strategies. At several points in the program, the patient needed to answer questions correctly to continue. The tablet retained responses linked to a study identification about alcohol consumption, history of past and current illicit drug use, sexual risk behavior, and offered risk reduction messages. The tablet content and presentation reflected suggestions by Hispanic patient-reviewers about cultural appropriateness and comprehension.

\section{Project Implementation and Maintenance Phase}

We report implementation of the program from December 1, 2012 to January 31, 2014. An automated EMR report classified all baby boomers admitted in the previous 24 hours as: (1) eligible with pending screening test order, (2) eligible without an order, (3) ineligible due to prior HCV test or diagnosis, or (4) ineligible due to comorbidity (eg, metastatic cancer). For approximately one-third of eligible patients, a study team member placed an order after review of the daily admission report because the order had not been automatically placed.

Admitting nurses initially asked for consent from eligible patients for HCV screening, but this was ultimately deemed too onerous a task along with all of their other duties. We then instituted opt-out consent with patient education about testing and opportunities to refuse via posters placed throughout the hospital and flyers in admission packets. A bilingual HCV counselor provided HCV screening test results to all patients. She counseled patients who screened positive for HCV with the educational program on an electronic tablet and developed a follow-up care plan.

A bilingual promotora (community health worker) contacted patients newly diagnosed with chronic HCV infection after hospital discharge to address the following: obtaining insurance, access to primary care and HCV specialty care, scheduling appointments, and treatment for alcohol problems or drug abuse. After obtaining signed consent, the promotora sent test results and recommendations for follow-up care (eg, hepatitis A and B immunization) to a designated outpatient physician and reminded patients about appointments and pending tests. The promotora received training in motivational interviewing skills to engage patients with needed care including alcohol treatment.

\section{Study Data}

A summary report was developed from the EMR with demographic, insurance, clinical, and HCV screening data for all admitted baby boomers. For patients diagnosed with chronic $\mathrm{HCV}$ infection, the promotora 


\begin{tabular}{|c|c|c|c|}
\hline Characteristic & $\begin{array}{l}\text { All Screened } \\
\text { Patients, No. }\end{array}$ & $\begin{array}{c}\text { Anti-HCV } \\
\text { Antibody-Positive } \\
\text { Patients, No. (Row \%) }\end{array}$ & $P$ Value $^{*}$ \\
\hline Overall & 3,168 & Total $=240(7.6)$ & \\
\hline Age, mean (SD) & $57.0(5.7)$ & $54.8(5.0)$ & $<0.0001$ \\
\hline \multicolumn{4}{|l|}{ Sex } \\
\hline Men & 1,771 & 185 (10.4) & \multirow[t]{2}{*}{$<0.0001$} \\
\hline Women & 1,397 & $55(3.9)$ & \\
\hline \multicolumn{4}{|l|}{ Race } \\
\hline Non-Hispanic white & 1,036 & $86(8.3)$ & \multirow[t]{4}{*}{0.12} \\
\hline Hispanic & 1,872 & $134(7.2)$ & \\
\hline African American & 163 & $17(10.4)$ & \\
\hline Other & 97 & $3(3.1)$ & \\
\hline \multicolumn{4}{|l|}{ Insurance } \\
\hline Insured & 1,740 & $109(6.3)$ & \multirow[t]{2}{*}{0.002} \\
\hline Uninsured & 1,428 & $131(9.2)$ & \\
\hline
\end{tabular}

NOTE: Abbreviations: HCV, hepatitis C virus; SD, standard deviation. ${ }^{*}$ From 2-sample $t$ test or $\chi^{2}$ test.

obtained data about follow-up HCV care through December 10, 2014 from the EMR, outside provider records, and patient reports.

\section{Study Variables}

The 2 outcome measures were a positive anti-HCV antibody test and positive HCV RNA test. Insurance status was categorized as insured (private, public, Veterans Administration, Department of Defense) or uninsured (self-pay or county-based financial assistance program). Problem drinking was identified from International Classification of Diseases, Ninth Revision, Clinical Modification codes for the admission, notes by clinicians describing alcohol abuse/dependence, or quantity/frequency meeting National Institute on Alcohol Abuse and Alcoholism criteria for alcohol problems of $>14$ drinks/week or $>4$ drinks/day for men and $>7$ drinks per week or $>3$ drinks per day for women. ${ }^{16}$

Implementation costs included informatics support, mobile app development, other patient educational materials, costs of screening tests for uninsured, and 0.3 full-time equivalent (FTE) of a clinician for half a year. Maintenance costs included salaries for the study team, HCV testing costs, and postage.

\section{Analysis}

Demographics by HCV antibody test results are compared using $\chi^{2}$ tests or Student $t$ tests as appropriate. Among persons with a positive HCV antibody test, HCV RNA results are similarly compared. This implementation project was approved by the University of Texas Health Science Center at San Antonio Institutional Review Board (HSC20130033N).

\section{RESULTS}

Within 14 months, 6410 unique baby boomers were admitted with a mean age 56.4 years (standard devia-

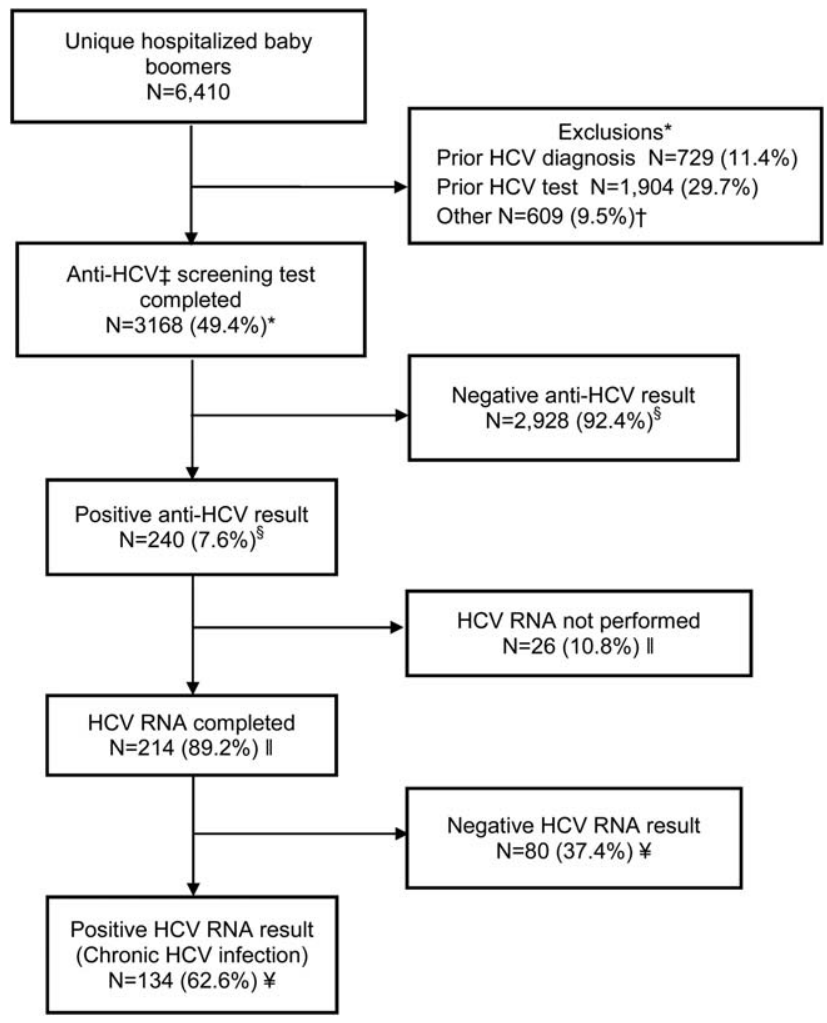

FIG. 1. Flowchart of all baby boomer patients born 1945 to 1965 hospitalized from December 1, 2012 through January 31, 2014, and HCV screening tests performed and test results. *Percent of unique admitted baby boomers. $\dagger$ Other exclusions: psychiatric hospitalization, metastatic carcinoma, poor prognosis based on clinician review, order not placed or canceled. $\ddagger A b=$ antibody. §Percent of patients tested for HCV Ab. ||Percent of patients testing positive for HCV Ab; test not performed when HCV Ab obtained inappropriate tube for reflex HCV RNA. ¥Percent of those tested for HCV RNA. Abbreviations: $\mathrm{Ab}$, antibody; HCV, hepatitis $\mathrm{C}$ virus.

tion [SD] 5.7), 55.9\% men, 59.1\% Hispanic, 8.2\% nonwhite, and $46.7 \%$ uninsured (Table 1). Among admitted patients, $729(11.4 \%)$ had a previous HCV diagnosis and 1904 (29.7\%) had been tested for HCV (Figure 1). Anti-HCV antibody testing was completed for 3168 (49.4\% of all admitted patients and $83.9 \%$ of never-tested patients). After exclusions such as significant comorbidity or psychiatric admission, $95 \%$ of eligible persons were tested. Of screened patients, 240 $(7.6 \%)$ were positive; these patients were significantly younger $(P<0.0001)$ and more likely to be men $(P<0.0001)$ and uninsured $(P=0.002)$ (Table 1$)$. Notably, $10 \%$ of men were anti-HCV positive versus $4 \%$ of women. In this predominantly Hispanic cohort, no significant difference appeared by race-ethnicity, but African Americans had a higher prevalence $(10.4 \%)$ than other groups.

HCV RNA testing was completed for $214(89.2 \%)$ anti-HCV-positive patients, of whom 134 (62.6\%) had detectable RNA, indicating chronic HCV infection (Figure 1). Overall, $4.2 \%$ of all eligible patients tested for HCV were chronically infected. No characteristics were significantly associated with chronic $\mathrm{HCV}$, but persons with chronic infection tended to be younger, uninsured, and African American (Table 2). 
TABLE 2. Demographic Characteristics of HCV RNA-Positive Patients

\begin{tabular}{|c|c|c|c|}
\hline Characteristics & $\begin{array}{l}\text { All HCV RNA-Tested } \\
\text { Patients, No. }\end{array}$ & $\begin{array}{c}\text { HCV } \\
\text { RNA-Positive } \\
\text { Patients, No. (Row \%) }\end{array}$ & $P$ Value ${ }^{*}$ \\
\hline Overall & 214 & $134(62.6)$ & \\
\hline Age, y, mean (SD) & $54.6(5.0)$ & $54.2(5.1)$ & 0.09 \\
\hline \multicolumn{4}{|l|}{ Sex } \\
\hline Men & 165 & $106(64.2)$ & 0.37 \\
\hline Women & 49 & $28(57.1)$ & \\
\hline \multicolumn{4}{|l|}{ Race } \\
\hline Non-Hispanic white & 78 & $49(62.8)$ & 0.65 \\
\hline Hispanic & 118 & $73(61.8)$ & \\
\hline African American & 15 & $11(73.3)$ & \\
\hline Other & 3 & $1(33.3)$ & \\
\hline \multicolumn{4}{|l|}{ Insurance } \\
\hline Insured & 92 & $52(56.5)$ & 0.11 \\
\hline Uninsured & 122 & $82(67.2)$ & \\
\hline
\end{tabular}

NOTE: Abbreviations: HCV, hepatitis C virus; SD, standard deviation. "From 2-sample $t$ test or $\chi^{2}$ test or Fisher exact test.

Among patients with chronic HCV infection, 129 $(96.3 \%)$ were counseled and follow-up plans developed (Figure 2). By December 10, 2014, 108 (80.6\%) patients had received follow-up primary care, and 52 $(38.8 \%)$ had care from a hepatologist. Five had initiated HCV-specific treatment, but many others were awaiting approval for compassionate drug programs offering direct-acting antivirals. Barriers to care included $82(61.2 \%)$ uninsured, $45(34 \%)$ problem drinkers, $22(16 \%)$ homeless, and $25(18.6 \%)$ incarcerated (not shown). The promotora addressed these issues by visiting homes or homeless shelters, assistance with obtaining county-based or other types of insurance, offering alcohol risk-reduction counseling, linking patients to alcohol-treatment programs, and communicating with the county jail about follow-up care.

Most of the developmental costs for the program were dedicated to developing EMR programs (Table
3). An optional cost was for the development of the tablet educational program about HCV. In regard to maintenance costs for the first 14 months, the majority was to support the program faculty, counseling/ case management, and a nurse practitioner who helped with ordering tests. We also estimated costs for testing uninsured patients $(45 \%$ of $\mathrm{HCV}$ antibody tested, $57 \%$ of HCV PCR tested, per Tables 1 and 2, respectively), as they must be borne by the hospital.

\section{DISCUSSION}

Implementation of universal HCV screening and linkage to care for hospitalized baby boomers utilizes a multicomponent infrastructure that reflects lessons learned from similar HIV programs. Use of an EMR algorithm to identify eligible patients and programs to automatically order HCV screening was a linchpin of our high testing rate and averted testing those who did not require screening. Of all 6410 baby boomers admitted to our safety-net hospital, the EMR screen identified over $40 \%$ as ineligible due to prior diagnosis of HCV infection or prior HCV tests. Most of the additional 609 patients who were not tested were excluded due to comorbidities or admission to psychiatry. Overall, the EMR programs, tests ordered by the team, and opt-out screening with education resulted in screening $95 \%$ of eligible patients. However, this program carries substantial costs, nearly $\$ 300,000$ for the first 2 years, for unreimbursed services in this safety-net hospital. The new guidelines for HCV screening ${ }^{1,2}$ are not accompanied by financial support either for program implementation or for screening and linkage to care for the uninsured, creating significant financial hurdles to achieve guideline compliance within already overtaxed public healthcare systems.

The infrastructure implemented in this hospital succeeded in achieving a higher rate of HCV screening of baby boomers than reported by other programs. In an emergency department in Birmingham, Alabama, a

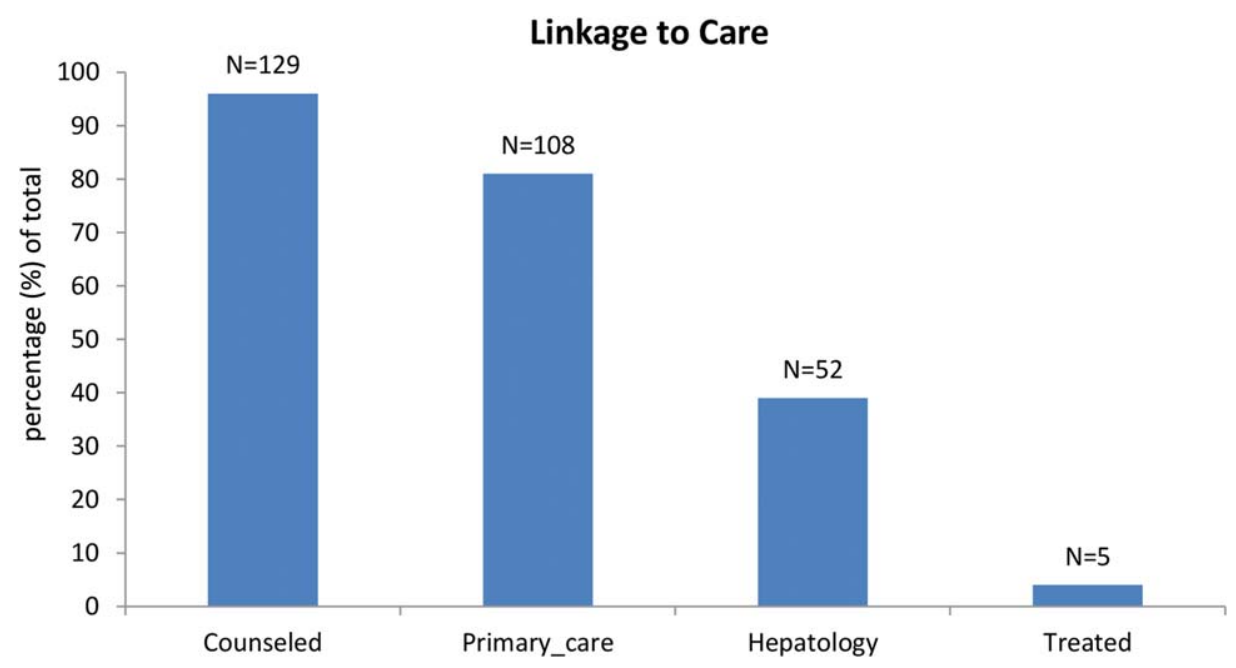

FIG. 2. Counseling and outpatient care by December 10, 2014 for patients with newly diagnosed chronic hepatitis $C$ virus infection from the inpatient screening program from December 1, 2012 through January 31, 2014. Abbreviations: Ns, not significant. 


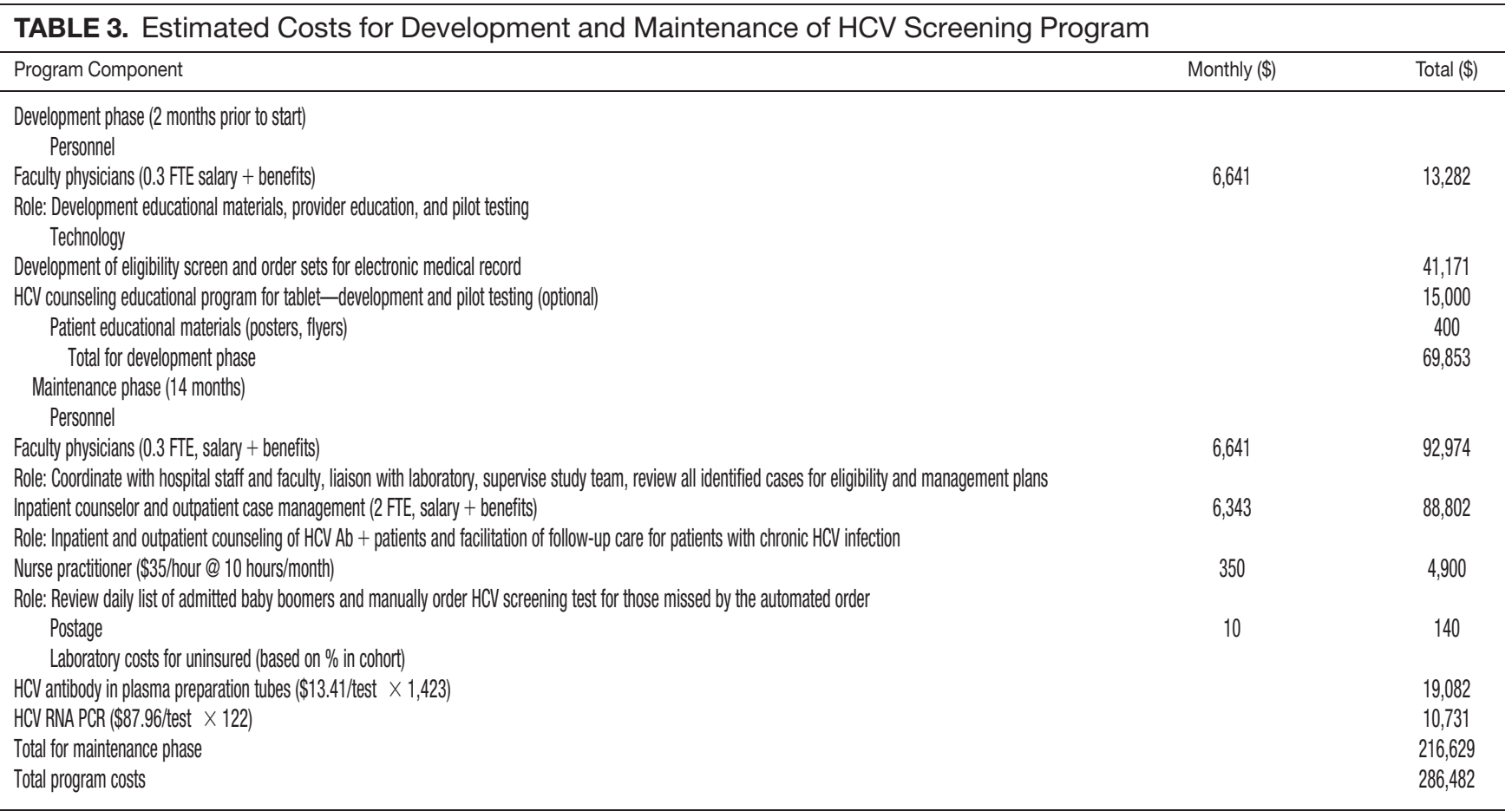

NOTE: Abbreviations: $A b$ = antibody; $F T E$, full-time equivalent; $H C V$, hepatitis $C$ virus; $P C R$, polymerase chain reaction.

screening program for baby boomers tested $66 \%$ of 2325 persons who were "HCV-unaware." 17 In an outpatient clinic for men who have sex with men, only $54 \%$ of 1329 patients were screened for HCV. ${ }^{18}$

Among 3168 screened patients in our cohort, 7.6\% were anti-HCV antibody positive, which is over twice the prevalence of $3.5 \%(95 \%$ confidence interval: $2.2 \%-4.8 \%$ ) for anti-HCV-positive tests in baby boomers based on National Health and Nutrition Examination Survey (NHANES) data from 2001 to 2010. ${ }^{19}$ However, the Alabama emergency department study found that $11 \%$ of tested patients were antiHCV positive. ${ }^{17}$ Although that study lacked raceethnicity data for half of the subjects, among those with this information, $13 \%$ of black and $7 \%$ of white subjects tested anti-HCV positive. Compared with the Alabama study, the anti-HCV prevalence in our cohort was somewhat lower for blacks $(10.4 \%)$ but higher for non-Hispanic whites $(8.3 \%)$. Hispanics in our cohort had the lowest anti-HCV prevalence $(7.2 \%)$, whereas the Alabama study did not report this figure. National studies also find that the prevalence of anti-HCV-positive results is twice as high for blacks compared with non-Hispanic whites and Hispanics, and nearly twice as high for men compared with women. ${ }^{19}$ In our cohort, the proportion of men with anti-HCV-positive results was nearly 3 times that for women.

Diagnosis of chronic HCV infection requires 2 tests, similar to performing a Western blot test after a positive enzyme-linked immunoassay for HIV. In a Veterans Affairs study, only $64 \%$ of patients with a positive
anti-HCV antibody test had a HCV RNA performed when reflex testing was not performed, and patients had to come in for a second test versus $>90 \%$ of patients in sites that offer reflex testing. ${ }^{20}$ At a somewhat increased price due to using more expensive PPTs (\$96/100 PPT tubes vs $\$ 6.50 / 100$ for serum “red top" tubes), both tests were performed on the same blood sample, resulting in $89 \%$ of anti-HCV antibody-positive patients being tested for HCV RNA.

Overall, $62 \%$ of patients in our cohort with a positive anti-HCV antibody test had HCV RNA detected (viremic) compared with $71 \%$ of persons aged $\geq 20$ years in an NHANES study from 2003 to $2010 .^{21}$ Several factors may contribute to this lower rate of chronic infection. In a study of HCV seropositive blood donors, Hispanics and non-Hispanic whites were significantly more likely to have spontaneously cleared HCV infection than Asians and non-Hispanic blacks. $^{22}$ Spontaneous clearance of $\mathrm{HCV}$ has also been associated with younger age at infection and HCV genotype $1 .^{23}$ Poorly understood genetic factors may also play a role. ${ }^{24}$ The high rate of HCV clearance in our cohort reinforces the need to perform HCV RNA testing.

Overall, $4.2 \%$ of our cohort had chronic HCV infection. According to CDC estimates from 1999 to 2008 NHANES data, 2.74 million $(3.25 \%)$ of 84.2 million US baby boomers have been infected with $\mathrm{HCV}$, and 2.04 million $(2.4 \%)$ have chronic infection. ${ }^{1}$ Therefore, our safety-net cohort of never-tested baby boomers had over twice the prevalence of chronic HCV infection than the national estimate for 
this age group. This high proportion of chronic HCV may reflect our predominantly low-income patient population. An analysis conducted by Milliman, Inc. using 2010 data estimated that half of all persons with undiagnosed $\mathrm{HCV}$ infection are uninsured. ${ }^{25}$ This finding reinforces the need to conduct HCV screening in acute-care settings such as hospitals, because the uninsured have poor access to ambulatory care.

Our chronic HCV-infected cohort had many barriers to follow-up care because most were uninsured and $15 \%$ were homeless. Our counselors addressed socioeconomic barriers to care ${ }^{26}$ and concerns about the disease. ${ }^{27}$ Many patients also had problem drinking based on either self-report or documented in the medical record. Even moderate alcohol use may increase the risk of overall and liver-related mortality from chronic HCV infection, ${ }^{28}$ so our team offered brief alcohol counseling and partnered with healthcare providers and local Alcoholics Anonymous programs to offer support.

We linked $80 \%$ of newly diagnosed patients to primary care or hepatology providers, aided by a countylevel financial assistance program for healthcare services for uninsured residents, but it still required patients to pay out of pocket for care. Access to newer, highly effective, all-oral therapy treatment ${ }^{5}$ was slowed while awaiting US Food and Drug Administration approval in the first year of this project, then treatment provided only after lengthy applications to drug company assistance programs with priority given to persons with compensated cirrhosis.

Our project raises serious concerns for policymakers and payers. Should universal baby boomer HCV testing be undertaken without taking into account the financial and personnel resources required to implement this screening program or the substantial expenditures necessary to treat chronically infected persons? Although the Centers for Medicaid and Medicare Services pay for HCV screening costs, ${ }^{29}$ our hospital had to cover costs for uninsured persons. Admittedly, Texas has the highest proportion of residents who are uninsured in the nation, but even in other states, Medicaid and other insurance programs are wrestling with how to deal with the high cost of HCV therapy. ${ }^{30}$

We acknowledge several limitations of this project. First, it was undertaken in only 1 hospital. Yet, our challenges and solutions are likely to be applicable to other hospitals nationally, especially those serving vulnerable populations. Second, patients in our cohort were usually admitted for comorbidities that needed to be managed before $\mathrm{HCV}$ infection could be addressed. However, persons with a poor prognosis, such as metastatic cancer, were excluded. We did not attempt to exclude other persons with serious comorbidities such as congestive heart failure, because the guidelines do not currently recommend this, and there may be benefits for patients, their families, and pro- viders from knowing that an individual is chronically $\mathrm{HCV}$ infected even if they are not eligible to be treated. Third, the cost of the program was supported in part by a grant and would otherwise have to be borne by the hospital. Fourth, the EMR used by our hospital allows hundreds of admission order sets to be created and made automated order entry hard to implement. This is unlikely to be the situation in other hospitals using different types of EMRs.

It remains to be seen whether safety-net hospitals with populations at greater risk of HCV infection can afford to support HCV testing and linkage to care. In view of several cost-effectiveness studies that find screening and treating chronic HCV-infected baby boomers cost-effective within standard thresholds, ${ }^{31-33}$ it may be important for policymakers and payers to consider lessons from HIV programs. Because HIV-infected persons could not afford lifesaving medication, vigorous advocacy efforts led to legislation approving the Ryan White program in 1990 to fill gaps in HIV care that were not covered by other sources of support. ${ }^{34} \mathrm{HCV}$ infection is the most common blood-borne infection in the nation, with potentially devastating consequences if ignored, but the underlying premise that universal HCV testing will save lives is in question if most of the individuals who are diagnosed with chronic HCV are low income, uninsured, or underinsured with limited access to curative medications. A rigorous public policy debate regarding both the merits of screening and the availability of treatment to those who are diagnosed is essential to the success of these programs.

Disclosure: Funding for this study was received from the Centers for Disease Control and Prevention CDC PS12-1209PPHF12. The authors report no conflicts of interest.

\section{References}

1. Smith BD, Morgan RL, Beckett GA, Falck-Ytter Y, Holtzman D, Ward JW. Centers for Disease Control and Prevention. Recommendations for the identification of chronic hepatitis $\mathrm{C}$ virus infection among persons born during 1945-1965. MMWR Recomm Rep. 2012;61: $1-32$.

2. 2. Centers for Disease Control and Prevention. Vital signs: evaluation of hepatitis $\mathrm{C}$ virus infection testing and reporting-eight U.S. sites, 2005-2011. MMWR Morb Mortal Wkly Rep. 2013;62:357-361.

3. Chak E, Talal AH, Sherman KE, Schiff ER, Saab S. Hepatitis C virus infection in USA: an estimate of true prevalence. Liver Int. 2011;31: 1090-1101.

4. Institute of Medicine. Hepatitis and liver cancer: a national strategy for prevention and control of hepatitis B and C. Washington, DC: The National Academies Press; 2010.

5. Liang TJ, Ghany MG. Current and future therapies for hepatitis C virus infection. N Engl J Med. 2013;368:1907-1917.

6. Kanwal F, Hoang T, Kramer JR, et al. Increasing prevalence of HCC and cirrhosis in patients with chronic hepatitis $\mathrm{C}$ virus infection. Gastroenterology. 2011;140:1182-1188.

7. U.S. Preventive Services Task Force. Screening for hepatitis C virus infection in adults: U.S. Preventive Services Task Force recommendation statement. Ann Intern Med. 2013;159:349-357.

8. Brady KA, Weiner MJ, Turner BJ. Undiagnosed hepatitis C on the general medicine and trauma services of two urban hospitals. I Infect. 2009;59:62-69.

9. U.S. Preventive Services Task Force. Screening for HIV: U.S. Preventive Services Task Force recommendation statement. Ann Intern Med. 2013;159:51-60.

10. Berkenblit GV, Sosman JM, Bass M, et al. Factors affecting clinician educator encouragement of routine HIV testing among trainees. J Gen Intern Med. 2012;27:839-844. 
11. Walensky RP, Reichmann WM, Arbelaez C, et al. Counselor-versus provider-based HIV screening in the emergency department: Results from the universal screening for HIV infection in the emergency room (USHER) randomized controlled trial. Ann Emerg Med. 2011;58: S126-S132.e1-4.

12. Greenwald JL, Hall J, Skolnik PR. Approaching the CDC's guidelines on the HIV testing of inpatients: physician-referral versus nonreferralbased testing. AIDS Patient Care STDS. 2006;20:311-317.

13. Centers for Disease Control and Prevention (CDC). Testing for HCV infection: an update of guidance for clinicians and laboratorians. MMWR Morb Mortal Wkly Rep. 2013;62:362-365.

14. Advia Centaur Assay Manual. Malvern, PA: Siemens Medical Solutions Diagnostics; Pub\# 07063235, Rev. C, 2005-01.

15. Taylor P, Pickard G, Gammie A, Atkins M. Comparison of the ADVIA Centaur and Abbott AxSYM immunoassay systems for a routine diagnostic virology laboratory. J Clin Virol. 2004;30:S11-S15.

16. National Institute on Alcohol Abuse and Alcoholism. Drinking levels defined. Available at: http://www.niaaa.nih.gov/alcohol-health/overview-alcohol-consumption/moderate-binge-drinking. Accessed June $12,2014$.

17. Galbraith JW, Franco RA, Donnelly JP, et al. Unrecognized chronic hepatitis $\mathrm{C}$ virus infection among baby boomers in the emergency department. Hepatology. 2015;61:776-782.

18. Hoover KW, Butler M, Workowski KA, et al. Low rates of hepatitis screening and vaccination of HIV-infected MSM in HIV clinics. Sex Transm Dis. 2012;39:349-353.

19. Ditah I, Ditah F, Devaki P, Ditah C, Kamath PS, Charlton M. The changing epidemiology of hepatitis $C$ virus infection in the United States: National Health and Nutrition Examination Survey 2001 through 2010. J Hepatol. 2014;60:691-698.

20. Rongey CA, Kanwal, Hoang T, Gifford AL, Asch SM. Viral RNA testing in hepatitis C antibody-positive veterans. Am J Prev Med. 2009; 36:235-238.

21. Denniston MM, Jiles RB, Drobeniuc J, et al. Chronic hepatitis C virus infection in the United States: National Health and Nutrition Examination Survey 2003 to 2010. Ann Intern Med. 2014;160:293-300.

22. Busch MP, Glynn SA, Stramer SL, et al. NHLBI Retrovirus Epidemiology Donor Study (REDS) Group. Correlates of hepatitis C virus (HCV) RNA negativity among HCV-seropositive blood donors. Transfusion. 2006;46:469-475.
23. Rolfe KJ, Curran MD, Alexander GJ, Wodall T, Andrews N, Harris HE. Spontaneous loss of hepatitis $C$ virus RNA from serum is associated with genotype 1 and younger age at exposure. J Med Virol. 2011; 83:1338-1344.

24. Grebely J, Dore GJ, Kim AY, et al. Genetics of spontaneous clearance of hepatitis $\mathrm{C}$ virus infection: a complex topic with much to learn. Hepatology. 2014;60:2127-2128.

25. Fitch K, Iwasaki K, Pyenson B, Engel T. Health care reform and hepatitis C: a convergence of risk and opportunity. Available at: http://us. milliman.com/uploadedFiles/insight/2013/convergence-of-risk-andopportunity.pdf. Accessed February 5, 2015.

26. Tohme RA, Xing J, Liao Y, Holmberg SD. Hepatitis C testing, infection, and linkage to care among racial and ethnic minorities in the United States, 2009-2010. Am J Public Health. 2013;103:112-119.

27. McGowan CE, Fried MW. Barriers to hepatitis C treatment. Liver Int. 2012;32:151-156.

28. Younossi ZM, Zheng L, Stepanova M, Venkatesan C, Mir HM. Moderate, excessive or heavy alcohol consumption: Each is significantly associated with increased mortality in patients with chronic hepatitis C. Aliment Pharmacol Ther. 2013;37:703-709.

29. Centers for Medicare and Medicaid Services. Proposed decision memo for screening for hepatitis c virus (HCV) in adults (CAG-00436N). Available at: http://www.cms.gov/medicare-coverage-database/ details/nca-proposed-decision-memo.aspx?NCAId=272. Accessed June 2, 2014.

30. Hoofnagle JH, Sherker AH. Therapy for hepatitis C-the costs of success. N Engl J Med. 2014;370:1552-1553.

31. McGarry LJ, Pawar VS, Panchmatia HR, et al. Economic model of a birth cohort screening program for hepatitis C. Hepatology. 2012;55: 1344-1355.

32. Liu S, Cipriano LE, Holodniy M, Goldhaber-Fiebert JD. Cost-effectiveness analysis of risk-factor guided and birth-cohort screening for chronic hepatitis C infection in the United States. PLoS One. 2013;8: e58975.

33. Rein DB, Smith BD, Wittenborn JS, et al. The cost-effectiveness of birth-cohort screening for hepatitis C antibody in U.S. primary care settings. Ann Intern Med. 2012;156:263-270.

34. U.S. Department of Health and Human Services. Health Resources and Services Administration: HIV/AIDS programs. Available at: http://hab. hrsa.gov/abouthab/legislation.html. Accessed April 8, 2015. 